\title{
Pelatihan Pemanfaatan Daun Kelor Menjadi Kelor Celup sebagai Minuman Kesehatan Tubuh di Gili Timur, Bangkalan
}

\author{
Mohammad Arief Wahyudi \\ Sekolah Tinggi Keguruan dan Ilmu Pendidikan PGRI Bangkalan \\ arwah74@stkippgri-bkl.ac.id \\ Joko Septaryanto \\ Sekolah Tinggi Keguruan dan Ilmu Pendidikan PGRI Bangkalan \\ joko@stkippgri-bkl.ac.id
}

Naskah diterima: 13 Desember 2019| Naskah disetujui: 17 Januari 2020

\begin{abstract}
People of Nangkek in East Gili, Madura, have a very simple life with livelihoods as builders, porters, seasonal farmers and unemployee. Daily necessities such as vegetables are obtained by planting plants in the front or back of the house such as chillies, spinach, and Moringa trees. To satisfy needs of vegetables, they pick, for example, vegetables from Moringa leaves. It is commonly understood that Moringa leaves are very good for our bodies and brings many benefits for our healthiness. Proposers through Community Service provide training on Moringa leaves becoming a Moringa dye for body health. This activity aims to develop entrepreneurship of each household to support the development of the creative economy. The results of these activities include: 1) increasing the entrepreneurship spirit of each head of household in an effort to support the community development activities; 2) the entrepreneurial community has business planning capabilities; 3) increasing the ability of the entrepreneurial community in conducting business operations. The method used is training, assistance and evaluation that is carried out during the community service program until the partners are able to develop the business well. It is finally concluded that as the partner (homemade), they will be creative and productive for their family's income.
\end{abstract}

Keywords: Utilization, Moringa leaf packaging, Health

\begin{abstract}
Abstrak
Masyarakat Nangkek di Gili Timur, Madura, memiliki kehidupan yang sangat sederhana dengan mata pencaharian sebagai kuli bangunan, kuli angkut, petani musiman, dan pengangguran. Kebutuhan sehari-hari seperti sayuran diperoleh dengan menanam tanaman di bagian depan atau belakang rumah seperti cabe, bayam, dan pohon kelor. Untuk memenuhi kebutuhan sayuran,
\end{abstract}


mereka memilih, misalnya, sayuran dari daun kelor. Secara umum dipahami bahwa daun kelor sangat baik untuk tubuh dan membawa banyak manfaat bagi kesehatan kita. Pengusul melalui program Pengabdian kepada Masyarakat memberikan pelatihan tentang daun kelor menjadi minuman kelor celup untuk kesehatan tubuh. Kegiatan ini bertujuan untuk mengembangkan kewirausahaan setiap rumah tangga untuk mendukung pengembangan ekonomi kreatif. Hasil dari kegiatan ini meliputi: 1) meningkatkan semangat kewirausahaan setiap kepala rumah tangga dalam upaya mendukung kegiatan pengembangan masyarakat; 2) komunitas wirausaha memiliki kemampuan perencanaan bisnis; 3) meningkatkan kemampuan komunitas wirausaha dalam melakukan operasi bisnis. Metode yang digunakan adalah pelatihan, pendampingan dan evaluasi yang dilakukan selama program pengabdian masyarakat sampai para mitra mampu mengembangkan bisnis dengan baik. Akhirnya disimpulkan bahwa sebagai mitra, mereka akan kreatif dan produktif untuk pendapatan keluarga mereka.

Kata kunci: Pemanfaatan, Pengemasan daun kelor, Kesehatan

\section{Pendahuluan}

Masyarakat Dusun Nangkek Desa Gili Timur kehidupannya sangat sederhana, dengan mata pencaharian sebagai tukang bangunan, kuli, petani musiman, bahkan juga masih ada yang menganggur. Untuk mencukupi kebutuhan sehari- hari mereka memanfaatkan hasil menanam tanaman di pekarangan rumah. Beraneka ragam sayuran yang ditanam seperti cabe, bayam, kangkung, dan pohon kelor.

Pohon kelor di masyarakat Dusun Nangkek Desa Gili Timur sudah menjadi tanaman yang selalu ada di setiap rumah. Dikarenakan setiap rumah selalu ada maka jika ingin memanfaatkan tumbuhan ini tinggal mengambilnya saja. Misalnya jika ingin membuat sayur daun kelor mereka tinggal memetik di pekarangan rumah. Pohon kelor di Indonesia sudah dikenal luas sebagai tanaman obat khususnya di daerah pedesaan, tetapi belum dimanfaatkan secara maksimal dalam kehidupan sehari-hari (Hariana, 2008).

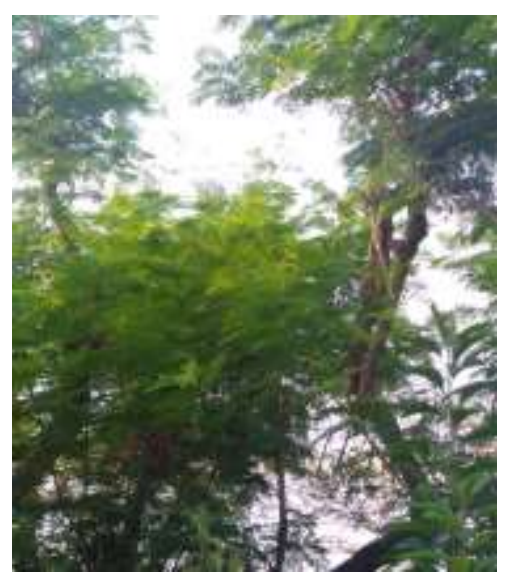

Gambar 1. Pohon Kelor 
Daun kelor yang memiliki nama latin Moringa oleifera lamk memiliki maanfaat sangat baik bagi tubuh, yaitu:

1. Menurunkan tekanan darah,

2. Mengurangi kolesterol,

3. Meningkatkan kinerja jantung,

4. Mengurangi kadar gula dalam darah atau diabetes, sebagai antioksidan,

5. Mengeluarkan racun dalam tubuh, anti kanker, tumor,

6. Mencegah kerusakan hati dan ginjal,

7. Mengatasi kemandulan,

8. Mempercepat reproduksi sel darah merah,

9. Memperkuat Rahim,

10. Membantu meringankan sakit pegal karena asam urat dan rematik.

Kelor sarat dengan fitonutrien yang merupakan nutrisi nabati yang diyakini memiliki efek mendukung kesehatan. Kelor telah lama digunakan untuk memerangi penyakit kardiovaskuler, obesitas, kolesterol dan juga merupakan elemen penting dalam membangun dan memperbaiki sel- sel dalam tubuh. pendapat Kurniasih (2012) bahwa Betasitosterol adalah komponen dalam kelor yang dapat membantu mengatasi masalah kolesterol. Kelor menjadi sumber antioksidan alami yang baik karena kandungan dari berbagai jenis senyawa antioksidan seperti vitamin C, flavonoid, phenolic dan karotenoid (Becker \& Makkar, 1996). Daun kelor juga mengandung Vitamin $\mathrm{C}$ lebih banyak dibanding jeruk dan kalsium empat kali lipat kalsium susu (Sutanto, dkk., 2007).

Dari manfaat tersebut maka kami sebagai pengusul melalui program Pengabdian kepada Masyarakat mencoba memberikan pelatihan pemanfaatan daun kelor menjadi minuman kelor celup untuk kesehatan tubuh. Di samping melaksanakan pengabdian, pengusul juga bekerja sama dengan mitra lain, salah satunya bekerja sama dengan praktisi usaha kelor rumahan (homemade) Agus Sejahterah yang berlokasi di Dusun Nangkek, Desa Gili Timur, Kec. Kamal, Kab. Bangkalan, Pulau Madura. Mitra tersebut mendukung dengan adanya kerja sama dalam pelatihan dalam pengemasan daun kelor menjadi minuman kelor celup untuk kesehatan tubuh yang diusulkan oleh tim.

Dalam mendukung keberlangsungan usaha dalam pemanfaatan daun kelor menjadi minuman kelor celup untuk kesehatan perlu adanya dukungan dari sumber daya yang memadai. Dukungan dukungan tersebut antara lain;

1. Sumber daya manusia, produksi minuman sehat dari daun kelor tidak memerlukan keahlian khusus, sehingga pemberdayaan ibu-ibu rumah tangga di Dusun Nangkek 
sangat memungkinkan untuk diberdayakan, sehingga pengusul bekerjasama dengan mitra usaha cukup diberikan pelatihan serta pendampingan dalam pengemasan dalam bentuk minuman.

2. Sumber daya alam, di wilayah dusun Nangkek sebagaian besar masyarakatnya menanam pohon Kelor yang ditempatkan di pekarangan depan dan belakang rumah, sehingga tidak ada masalah di ketersediaan bahan baku.

\section{Permasalahan Mitra dan Solusi yang Ditawarkan}

Ketidaktahuan dari manfaat daun kelor untuk kesehatan, dikarenakan kurangnya informasi bagi pengelolah industri rumahan (homemade) di Gili Timur. Selama ini masyarakat tersebut hanya memanfaatkan daun kelor untuk kebutuhan sehari-hari saja, seperti untuk kebutuhan sayur-mayur. Maka dengan adanya program Pengabdian kepada Masyarakat, melalui Pelatihan Pemanfaatan dan Pengemasan daun kelor menjadi minuman kelor celup yang berkhasiat bagi kesehatan tubuh akan memberikan kontribusi yang baik untuk peningkatan pendapatan mitra yaitu Agus Sejahterah serta meningkatkan kreatifitas dan inovasi masyarakat Dusun Nangkek.

Dengan pemanfaatan Daun kelor menjadi minuman kelor celup untuk kesehatan tubuh diharapkan bisa membantu peningkatan produksi pengelolahan kelor yang lebih baik. Adapun tujuan praktis yang ingin dicapai dalam kegiatan ini adalah:

1. Memberikan informasi tentang manfaat daun kelor

2. Pelatihan pengemasan daun kelor menjadi Kleor celup dalam kemasan minuman

3. Membuat minuman kesehatan tubuh

4. Pendampingan pembuatan Kelor Celup sebagai usaha meningkatkan pendapatan produktivitas bagi pengelola Homemade.

\section{Pelaksanaan dan Metode}

Dalam menyelesaikan masalah tersebut di atas maka pengusul menggunakan metode pelaksanaan kegiatan beserta solusi yang digunakan dalam mengatasi masalah tersebut.

\section{Tahap Persiapan}

Pelaksanaan kegiatan ini dimulai dengan tahap persiapan yaitu mempelajari referensi terkait dengan pengumpulan data dengan cara mengadakan survey lapangan dan tanya jawab tentang keberadaan masyarakat di Dusun Nangkek Gili Timur Bangkalan. 


\section{Tahap Pelaksanaan}

Kegiatan ini dilaksanakan di Dusun Nangkek Desa Gili Timur Kecamatan Kamal Bangkalan yang diikuti oleh pengusul program pengabdian kepada masyarakat bekerjasama dengan Agus Sejahterah dan dibantu 5 mahasiswa.

Diawali dengan langkah pengusul mengadakan pendekatan dengan mitra tentang persiapan yang akan dilaksanakan dalam program PKM, kemudian pengusul menyusun jadwal pelatihan tentang pengemasan daun kelor menjadi teh kelor celup untuk kesehatan sebagaimana tabel 1.

Tabel 1. Rundown Kegiatan PKM di Dusun Nangkek

\begin{tabular}{|l|c|c|}
\hline \multicolumn{1}{|c|}{ Tanggal } & Waktu & \multicolumn{1}{|c|}{ Kegiatan } \\
\hline 7 September & $08.00-09.30$ & $\begin{array}{l}\text { Persiapan: Survei lapangan, mencari } \\
\text { informasi/ gambaran dan mencatat hal- } \\
\text { hal tentang masyarakat desa Nangkek } \\
\text { kelurahan Gili Timur }\end{array}$ \\
\hline 15 Oktober & $09.00-$ selesai & $\begin{array}{l}\text { 1. Penyuluhan tentang manfaat daun } \\
\text { kelor, Diskusi berupa Tanya jawab } \\
\text { serta pengambilan daun kelor untuk } \\
\text { dijemur selama 3- 4 hari tanpa kena } \\
\end{array}$ \\
& & $\begin{array}{l}\text { sinar matahari dan dokumentasi/ foto } \\
\text { Pendampingan dan pegelolahan daun } \\
\text { kelor dengan cara diblender }\end{array}$ \\
& &
\end{tabular}

Dalam pelaksanaan program yang dilakukan, mendapatkan respon yang sangat positif dan antusias sehingga akan membuka wawasan bagi masyarakat Dusun Nangkek Desa Gili Timur dalam memanfaatkan daun kelor yang tadinya sebagai sayur-mayur dan sekarang menjadi minuman sehat dalam bentuk kelor celup. Dengan tampaknya antusiasme dan partisipasi tersebut, diharapkan masyarakat dapat memanfaatkan dan menciptakan suatu kreasi dan inovasi baru dalam memanfaatkan daun kelor.

\section{Tahap Penyelesaian}

Dalam tahapan ini adalah evaluasi dan penulisan laporan kegiatan pengabdian masyarakat, di mana tahap ini membutuhkan waktu selama empat minggu. Dan tahap ini merupakan tahap yang terpenting dalam pelaksanaan pengabdian tersebut serta juga akhir dari kegiatan. Pun demikian, 
terhadap mitra di Dusun Nangkek masih tetap diadakan pendampingan. Evaluasi dilakukan dalam rangka melihat kegiatan yang selama ini dilakukan, apakah tepat sasaran atau tidak, yang berguna untuk kegiatan kedepannya agar pengabdian kepada masyarakat ini terus berjalan dan memberikan manfaat khususnya kepada masyarakat Dusun Nangkek Desa Gili Timur dan umumnya kepada masyarakat luas. Penulisan laporan dimaksudkan untuk memberikan kontribusi keilmuan dalam pengabdian masyarakat dan umumnya kepada pembaca.

\section{Pembahasan}

Ada beberapa langkah yang dilakukan dalam kegiatan pengabdian masyrarakat ini guna kelancaran dan keberhasilan kegiatan. Langkah-langkah tersebut dirumuskan masyarakat bersama dengan mitra homemade Agus Sejahterah. Adapun implementasi dari perumusan tersebut sebagai berikut:

1. Pengarahan tentang manfaat pentingnya daun kelor, dengan tujuan menambah informasi. Dengan demikian masyarakat Dusun Nangkek Desa Gili Timur bisa memanfaatkan daun kelor yang selama ini dijadikan sayur berkuah sebagai pendamping nasi dan lauk pauk. Pengarahan ini dilakukan tanggal 15 Oktober 2019 pada jam 09.00 sampai selesai. Antusiasme masyarakat sangat besar sekali sehingga informasi yang didapat sangat mudah dipahami sekali. Maka hasil yang didapat dari informasi tersebut masyarakat akan berfikir untuk berkreasi dan berinovasi tentang bagaimana daun kelor bisa dimanfaatkan dalam produk lain.

2. Pendampingan dalam mengelola daun kelor menjadi minuman kelor celup untuk kesehatan tubuh perlu dilakukan agar bisa menghasilkan produktifitas yang baik dan masyarakat bisa mengetahui bagaimana proses pembuatan daun kelor menjadi minuman kelor celup. Ini dilakukan setelah adanya pengarahan dan kemudian langsung dipraktekkan.

3. Pendampingan adalah hal yang paling pokok penting walau kegiatan pengabdian kepada masyarakat telah selesai dilakukan, karena pengusul akan selalu memantau setiap kegiatan yang dilakukan masyarakat agar supaya produktifitas tetap berjalan dengan lancar. Apalagi banyaknya pohon Kelor yang ditanam oleh masyarakat menjadikan program ini dapat berkelanjutan.

Kelor celup termasuk inovasi baru dalam mengolah daun kelor yang ada di Dusun Nangkek Desa Gili Timur. Hal ini dikarenakan masyarakat pada umumnya hanya terbatas menjadikan sayur, 
sehingga masyarakat mendapatkan ilmu baru dalam mengolah daun kelor. Berikut adalah tata cara mengolah daun kelor menjadi minuman kelor celup;

1. Daun kelor dijemur atau diangin-anginkan di tempat yang dingin (bukan di bawah terik matahari) selama 3-4 hari. Dapat juga dengan cara di-oven selama 15 menit.

2. Jika sudah layu (tidak sampai kering) kemudian dihaluskan dengan blender sampai halus

3. Kemudian dimasukkan di kantong kertas tipis kecil kemasan seperti teh celup.
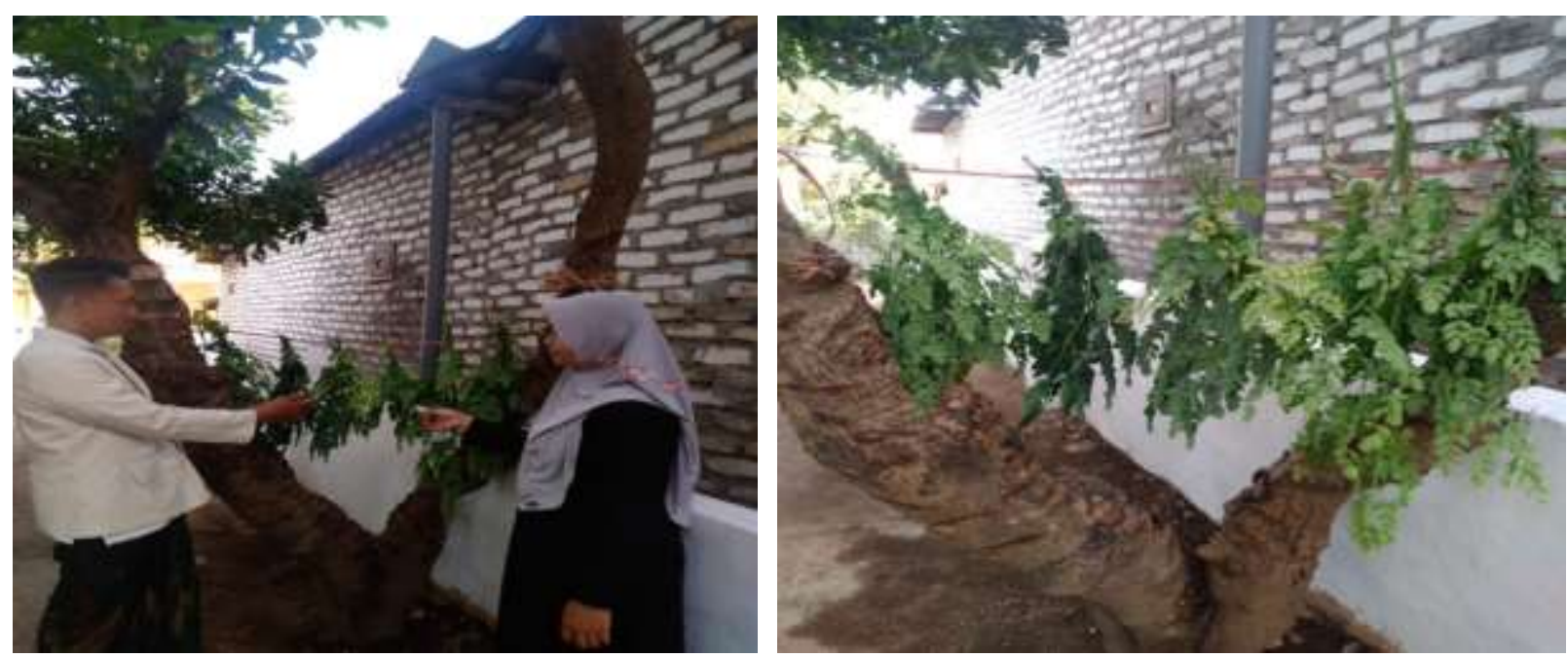

Gambar 2. Penjemuran daun kelor
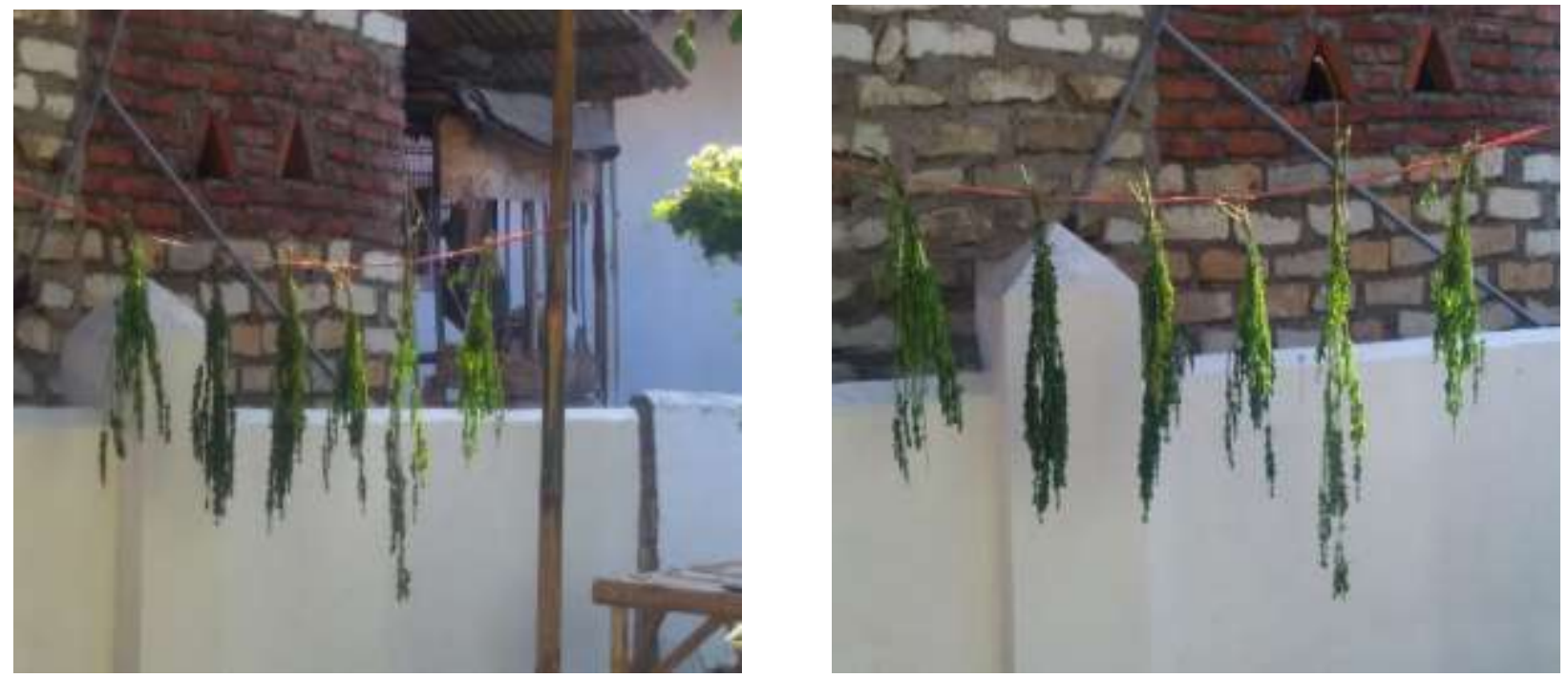

Gambar 3. Hasil penjemuran daun kelor 

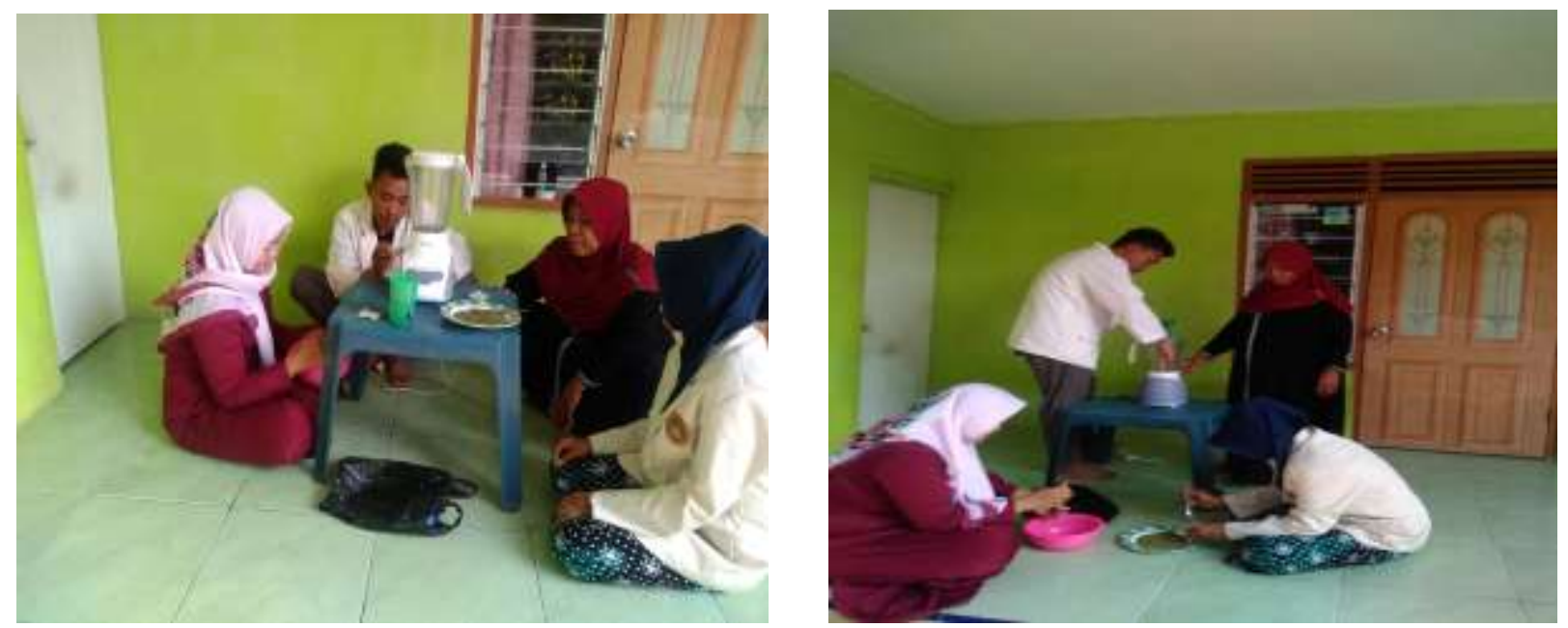

Gambar 4. Proses penghalusan

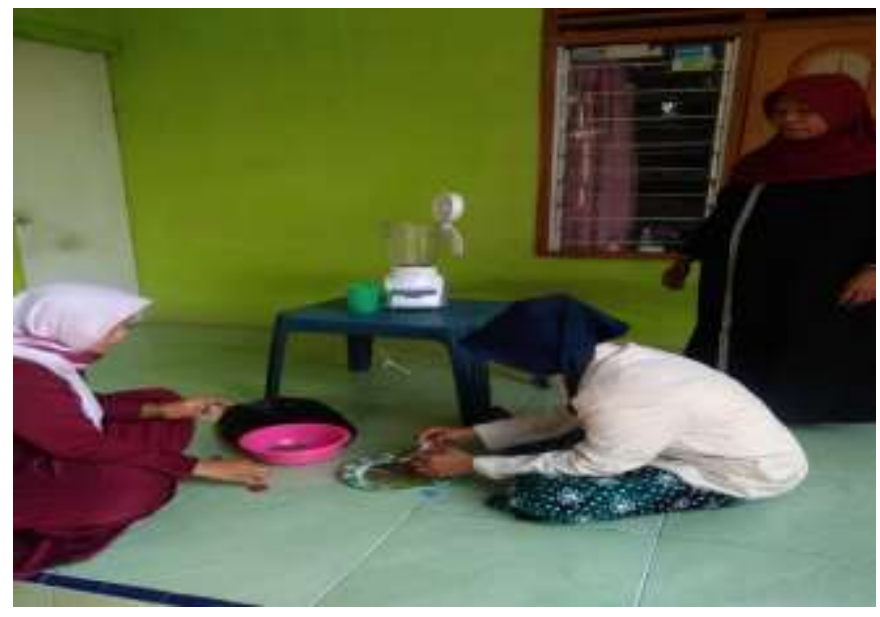

Gambar 5. Pengemasan dalam kemasan kecil untuk dijadikan kelor celup

Dengan adanya Program Pengabdian kepada masyarakat di Dusun Nangkek Gili Timur Kecamatan Kamal Kabupaten Bangkalan ini, diharapkan bisa memberikan manfaat kepada masyarakat. Yang semula daun kelor hanya sebagai sayur untuk konsumsi harian, dengan adanya pendampingan masyarakat maka dapat memberikan nilai jual terhadap daun kelor yang telah diolah menjadi kelor celup. Dan pada akhirnya, dari inovasi kelor celup tersebut dapat memberikan tambahan ekonomi pada masing-masing keluarga. Selain menjadi sumber tambahan ekonomi masyarakat dengan menjadikan kelor celup tersebut bisa menjadikan tubuh sehat.

\section{Kesimpulan}

Dari pendamingan masyarakat yang dilakukan bekerja sama dengan mitra homemade maka dapat disimpulkan sebagai berikut;

1. Dengan adanya Pengabdian Kepada Masyarakat, masyarakat akan lebih kreatif dan produktif mengolah sumberdaya alam utamanya adalah daun kelor, sehingga perekonomiannya menjadi lebih meningkat. 
2. Dari awalnya hanya sebagai sayur, dengan menjadikan minuman kelor celup maka akan semakin tinggi nilainya, karena pengemasan dan promosi manfaatnya bagi kesehatan tubuh.

3. Pendampingan masyarakat harus tetap terus dilakukan agar masyarakat terus berkembang dan mandiri. Jika sudah mandiri, pendamping baru dapat meninggalkan masyarakat.

Saran yang bisa diberikan sesudah pelaksanaan untuk para pendamping masyarakat, khususnya pendampingan masyarakat Dusun Nangkek Gili Timur Kamal Bangkalan adalah sebagai berikut:

1. Dalam pelakanaan program pengabdian, pelaksana hendaknya melakukan pendampingan yang lebih intensif sehingga mitra mampu menerapkan pengetahuan secara mandiri;

2. Pelaksanaan penuh keikhlasan dan kesabaran, jangan mengharap imbalan dan harus tekun, jika ingin pendampingan masyarakat berhasil;

3. Masyarakat Dusun Nangkek bisa memanfaatkan daun kelor dengan cara inovasi yang lain tidak terbatas pada kelor celup saja;

4. Perlu bekerja sama dengan pihak-pihak lain guna pengadaan barang elektronik berupa mixer (pengaduk) dan lain sebagainya agar proses pengabdian kepada masyarakat berjalan dengan lebih baik dan lancar.

\section{Pernyataan}

Ucapan terima kasih disampaikan kepada LPPM STKIP PGRI Bangkalan yang menyelenggarakan pengabdian kepada masyarakat yang mandiri serta mendanai kegiatan ini sampai artikel ini terbit. Dan tak lupa juga kepada mitra kerja Agus Sejahterah (Home Made) yang bersedia menerima kegiatan ini dan semoga apa yang pengusul lakukan dalam kegiatan ini dapat bermanfaat terhadap masyarakat, khususnya di Dusun Nangkek Gili Timur Bangkalan.

\section{Referensi}

Aminah, S., Ramdhan, T. \& Yanis, M. (2015). "Kandungan Nutrisi dan Sifat Fungsional Tanaman Kelor (Moringa oleifera)". Buletin Pertanian Perkotaan, 5 (2), 35-44. Balai Pengkajian Teknologi Pertanian Jakarta.

Anwar, F., Latif, S., Ashraf, M. \& Gilani, A.H. (2007). "Moringa oleifera: a food plant with multiple medicinal uses". Phytother. Res. 21, 17-25

Aritjahja, S. (2011). Kelor sejuta khasiat. Artikel. http://www.trubusonline.co.id. Diakses 18 April 2017.

Becker, K., \& Makkar, H.P.S. (1996). "Nutritional value and antinutritional component of whole and ethanol extracted moringa oleifera leaves". Journal of Feed Science and Tecnology, 63, $211-228$

Hariana. (2008). Tumbuhan obat dan khasiatnya. Jakarta: Niaga Swadaya.

Kurniasih. (2012). Khasiat dan Manfaat Daun Kelor untuk penyembuhan berbagai penyakit. Cetakan Pertama, Yogyakarta : Pustaka Baru Press. 
Mardiana, L. (2013). Daun Ajaib Tumpas Penyakit, Kanker, Diabetes, Ginjal, Hepatitis, Kolesterol dan Jantumg. Cet.4. Jakarta : Penebar Swadaya.

Sutanto, T., Adfa, D., \& Taringan, N. (2007). "Buah kelor (moringa oleifera lamk.) tanaman ajaib yang dapat digunakan untuk mengurangi kadar ion logam dalam air". Jurnal Gradien, 3(1), 219-221. 